\title{
LOCALIZED TORSIONAL STRENGTHENING TECHNIQUE FOR RC BOX BEAMS WITH TRANSVERSE OPENINGS
}

\section{${ }^{*}$ Ayoub Hamid Moatt ${ }^{1}$}

1,2) Collage of Engineering-Mustansiriyah University-Baghdad-Iraq

\author{
Ali Hameed Aziz ${ }^{2}$
}

\begin{abstract}
In the present study, experimental analysis was performed to investigate the effect of localized strengthening by steel plates on the torsional capacity of reinforced self-compacting concrete (SCC) box beams containing a transverse opening under pure torsional moments of seven hollow core beam specimens. The seven tested beam specimens were cast with the dimensions $(1800 \times 300 \times 300 \mathrm{~mm})$ respectively, for the length, width, and depth; six of them including transverse openings of dimensions $(100 \times 100 \mathrm{~mm})$. The parameter studies were: with or without transverse opening, the position of the transverse opening was at $(L / 4)$ and $(L / 2)$ of the clear span length of the beams (from one side or two sides). The current strengthening technique used depends on: the localized steel plates fabricated to be fully bonded with SCC through using bolts as shear connectors. The experimental results show the ultimate torque decreased by $(34.7 \%)$ and $(45.3 \%)$ for the tested specimens which contained transverse openings respectively at a distance (L/4) and (L/2), in comparison to the control beam. By the opposite side, the ultimate torsion moments were increased by (34\%) and $(55.5 \%)$ for the tested specimens which contained transverse opening at a distance (L/4) and respectively strengthened by (one and two) face localized steel plates, relative to the reference specimens. Whereas, the maximum torsional moments were raised by about (20\%) and $(24 \%)$ for the tested specimens containing transverse opening at a distance $(\mathrm{L} / 2)$ and strengthened by (one and two) face localized steel plates respectively, compared to the reference beam. , it concluded that torsional capacity has deteriorated because of the existing transverse
\end{abstract}

opening, and it has been enhanced due to the contribution of the approved technique.

Keywords: Transverse opening, Localized Strengthening.

\section{Introduction}

Wide-ranging work has been carried out over the last few years on the design of concrete structures under the influence of torsion, and then it can be assumed that such results of these researchers form the basis of regulatory requirements which can lead to secure as well as economic design concepts [1].

During the last few decades, one of the structural engineering complexities has been the presence of transverse openings in reinforced concrete beams, particularly, at highway bridges which containing box girders were the openings are used to pass mechanical, electrical and maintenance utilities (services) such as electricity services, telephone lines, water supply pipes, and computer network. Also in high elevated buildings, when the height of the floor not sufficient to place its utility below the beam soffit. Therefore, supplying the RC beams with openings, lead to create cracks around the openings which reduce the stiffness of the beam and brings necessity to local or global strengthening

*Corresponding Author: Abodyayoub@gmail.com 
techniques. Lately, much attention is devoted to the strengthening of the torsioned reinforced concrete (RC) beams; the torsion is a significant factor affecting the elements of the structural stability. The elements of the structures undergo torsion suffer diagonal tension and compression stresses, and fail in a fragile manner that can lead to a progressive building failure. [2].

Due to rapid development in concrete technology, various kinds of concrete, such as "Concrete with Ultra High Performance" (UHPC), "Reactive Powder Concrete" (RPC) and "Self-Compacting Concrete" (SCC) raised. Self-consolidation concrete (SCC) can be defined as high-performance concrete that can flow without using any vibrator machine under its own weight only to achieve suitable consolidation because of its high fluidity properties by filling the formwork, even when there are dense reinforcement areas and narrow gaps between bars [3].

Reinforced concrete sections under torsional stresses were interested in several researches;

Al-sa'idi, 2013 [4] studied the behavior of selfcompact RC beams under pure torsion. Experimental and analytical methods were used to test and analyze RC self-compact concrete (SCC) beams. Many parameters were focused by the author including tests of plain, RC, compressive strength, the percentage of steel fiber, and self-compacting. Twenty beams including normal and (SCC) were tested and subjected to pure torsion. The experimental results from this research proved that the use of concrete with high compressive strength and self-compact gives high torque capacity resistance.

Fawzy et al., 2014 [5] Investigated the structural behaviors of RC solid beams with transverse opening and strengthened with CFRP strips under pure torsion. The experimental work consists of pour and test nine RC beams of the same dimensions and the same reinforcement. The study concluded the provision of the opening in the beams leads to a noticed decrease in the cracking and ultimate torsional strength by (43\%) and (38\%) respectively; Also, The best results are obtained by strengthening the beam that contains opening using full $\left(90^{\circ}\right)$ wrapping around the chords and the solid part near the opening area, where the torsional strength increased by $(48 \%)$ of the control beam with opening and it became close to the torsional strength of the reference solid beam.

Waryosh et al, 2015 [6] examined ultimate strength related to the hollow RC beams within pure torsion. The experimental program includes eight beam specimens and used variable parameters such as concrete compressive strength and hollow geometry. The study includes a hollow section with different shapes and percentages (rectangular 18\%, circular $18 \%$ also $27 \%$ of beam's total cross section area) and solid section. Furthermore, the torque-twist, as well as hollow effects on it and on RCC beams' full behavior, have been examined in the study. The investigators indicated that the hollow section's full torque capacity in the case of circular has been more than in the case of rectangular hollow in comparison to the reference solid section, also the torque capacity is increased in the case of when increasing the compressive strength.

Mahdi, 2015 [7] Made an experimental study on six reinforced self-compacted hollow high strength concrete sections subjected to the effect of pure torsion. All beams were identically in cross section; $(300 * 300) \mathrm{mm}$ external dimensions and $(180 * 180)$ $\mathrm{mm}$ hollow dimensions. The main variable is the amount of transverse reinforcement where the other parameters were kept constant. The experimental results showed that, the percentages of the beams' mechanical properties enhance due to the reduction in stirrups' spacing according to the reference beam are: For ultimate torsional capacity extends between (25.7-254.3\%), for cracking capacity extends between (25-200\%), and for twisting angle extends between (23.3-76) \%.

Jabbar et al., 2016 [8] studied the torsional behavior of reinforced concrete (with High-Strength Concrete HSC and Ultra-High Performance Concrete UHPC) box beam with transverse web opening and compare it with a box beam without opening, in this research, The researchers examined five different sections of the beams: hollow beam $(\mathrm{H})$, solid section $(\mathrm{S})$, and hollow beam with square openings that measure 100 mm (H100), $200 \mathrm{~mm}$ (H200), and $300 \mathrm{~mm}$ (H300), The openings center-to center distance for all models 
was $(500 \mathrm{~mm})$. All beams were modeled in (ABAQUS software) as cantilever beams and subjected to torsional loadings of (400 KN. m) for HSC and (700 KN. m) for UHPC at the end of the beam to evaluate the effect of torsional load. The results indicated that the torsional capacity was sharply decreased when increasing the dimensions of the transverse opening.

Kandekar and Talikoti, 2019 [9] studied the torsional behavior of reinforced concrete beams strengthened by using aramid fiber strips to wrap the beams with different patterns. Twenty one reinforced concrete beams of rectangular section were cast and tested until failed in torsion. Different aramid fiber configuration effect on torsional capacity, twist angle and mode of failure of the beams is studied. It is seen that torsional moment carrying capacity increases when the beams was wrapped using aramid fiber strips. As strips spacing were increased, the torsional moment capacity decreases and the twist angle has small variations. In strengthened beams, Initial cracks occurred at higher torsional moments.

Ali and Oday, 2018 [10] Studied, experimentally, the torsional behavior of six SCC box beams strengthened with transverse concrete diaphragms which may be opened or closed. First beam was the reference beam of hollow section, second and third were strengthened by two closed and opened diaphragms, respectively, fourth and fifth were strengthened by four closed and opened diaphragms, respectively, and sixth was of solid section. Results showed that the ultimate torque increases by $43 \%$, $61 \%, 89 \%$, and $94 \%$ for strengthened second, third, fourth, and fifth beam specimens, respectively. Beam specimen of solid section has ultimate torque increment of $28 \%$ and $33 \%$ compared with fourth and fifth beam specimens. The cracking torque increased by 57\%, 29\%, 100\%, $86 \%$ for strengthened second, third, fourth, and fifth beam specimens, respectively. Toughness was higher in strengthened beam specimens.

Ali and Muhammad, 2018 [11] evaluated the improvement of the torsional strength of reinforced (SCC) hollow beams, strengthened internally with transverse steel bracing. Seven specimens of beams, were poured and tested under the effect of pure torsion. Two types of internal bracing, cross (Xtype) and welded cross (XW-type) were used. The first beam was the reference box beam. The ultimate torque moment increased by $(14.4 \%, 34.3 \%$, and $59.2 \%)$, twist angle decreased by $(8.2 \%, 18.8 \%$, and $30.365 \%)$, elongation decreased by $(8.2 \%, 21.7 \%$ and $33.3 \%$ ) for (second, third, and fourth) specimens which were strengthened by (one, three, and five) Xtype bracing, respectively. The ultimate torque moment increased by $(21.9 \%, 41.8 \%$, and $71.6 \%)$, twist angle decreased by $(12.3 \%, 26.2 \%$, and $32.42 \%)$, elongation decreased by $(17.3 \%, 26.6 \%$ and $40 \%$ ) for (fifth, sixth, and seventh) specimens which were strengthened by (one, three, and five) XW-type bracing, respectively.

Hadhood et al. , 2020 [12] evaluated the torsional strength of six tested beams reinforced with glass fiber-reinforced polymer (GFRP) reinforcement with rectangular spirals and rectilinear stirrups to strengthen concrete beams transversely under the effect of pure torsional loading. The studied variables contained four stages of the transverse reinforcement ratios and the form of transverse reinforcement in terms of rectilinear stirrups versus spirals. The test results revealed that rectangular (GFRP) spirals supplied excellent tensile resistance needed to create high ultimate torsional moments after cracking, and can, therefore, be used effectively.

\section{Research Significance}

The current paper aims to study the torsional behavior of (SCC) hollow beams, containing transverse openings as well as to investigate the impact of these openings on the torsional capacity of the beams. As well as showing the effectiveness of the localized steel plates as a strengthening method for such beams.

\section{Experimental work}

\subsection{Research experimental program}

The test program consisted of poured and tested of "seven" reinforced SCC hollow beams up to pure torsion failure. The beam specimens examined were 
divided into three categories; the first group is composed of one beam specimen without transverse opening and without strengthening. the second group is composed of one beam specimen without strengthening and two-beam specimens strengthened by lining the inner sides of one and two outer rims of the transverse opening by steel plates as a localized strengthening respectively. On the other hand, the third group contains three samples also, in the same format as the second group, but all six tested beams of the second and third groups include a transverse opening at (L/2 and L/4) respectively. The experimental program, also, includes a number of tests conducted on control samples (cubes, prisms and cylinders) to appraise the hardened selfcompacting concrete's mechanical properties as well as many tests to control fresh SCC. Also, the mechanical properties of the reinforcing steel bars and steel plates were tested for yield and ultimate strength. The major adopted variables including, the presence or absence of transverse opening, the position of transverse openings, at (L/4 and L/2) of the clear distance of beams, the presence or absence of strengthening by localized steel plates, number of steel plate in localized strengthen that covering the outer rims of the transverse opening (from one or two sides).

During the laboratory tests, the concrete grade, clear span, and loading condition, were left constant. All tested specimens were simply supported attached to rotatable supports. Ultimate and cracking loads, torque-longitudinal elongation behavior, torqueangle of twist behavior, mode of failure, and torquestrain relationships for (steel reinforcement, localized steel plates, and concrete) are presented, and discussed in this research. The adopted test methods for the fresh SCC are based on EFNARC specifications and guidelines for SCC [13].

\subsection{Beam specimens description}

Seven specimens of SCC box beams with dimensions of $(1800 \times 300 \times 300 \mathrm{~mm})$ for length, height, and width were cast and tested. The steel reinforcement is directly designed for torsions according to the provisions of the ACI-318M-14 code [14]. All beams have been reinforced longitudinally by $(2 \phi 12 \mathrm{~mm})$ bars at the top and by $(2 \phi 12 \mathrm{~mm})$ bars at the bottom; reinforced transversely by $(\phi 8 @ 50 \mathrm{~mm})$ at edges and ( $\phi 8 @ 130 \mathrm{~mm})$ at the mid.

Each specimen is named to refer to the section type (B =Box beam), the number of steel plates that covering the outer rims of the transverse opening (from one or two sides), and the location of transverse opening (L/2 and L/4). Therefore, for example, the beam specimen (B-1FS-0.5L) is a box beam which strengthened by lining the inner sides and one outer rim of the transverse opening by steel plate as a localized strengthening, and the transverse web opening at a beam's mid-span. The tested beams designation, dimensions, and details are provided in Table (1) and Figures (1) to (7).

The localized strengthening is manufactured by (one or two) vertical steel plates with dimensions (200x200x3mm) denotes to width, height, and thickness; interspersed with a hole in the middle with dimensions equal to the dimensions of the transverse opening $(100 x 100 \mathrm{~mm})$. These steel plates were welded with another one that lining the inner sides of the transverse opening in the $\mathrm{RC}$ beam. To ensure complete bonding between the placed localized steel plates and the concrete reinforced box beams, twelve head cap screw with a diameter of $(8 \mathrm{~mm})$ is used to fasten the inner and outer vertical steel plates, when using two face steel plates, as shown in Figure (8-a). Sixteen steel bolts of the diameter and length of (8mm and $35 \mathrm{~mm})$ respectively, have been welded on the inside face of the vertical steel plate when uses one face steel plate, as showed in Figure (8-b). 
Table 1. Details of the Tested Beam Specimens

\begin{tabular}{|c|c|c|c|c|c|c|}
\hline \multirow{2}{*}{ 总 } & \multirow{2}{*}{$\begin{array}{c}\text { Tested Beams' } \\
\text { designation }\end{array}$} & \multicolumn{3}{|c|}{$\begin{array}{c}\text { Dimensions } \\
\mathrm{mm}\end{array}$} & \multirow{2}{*}{ 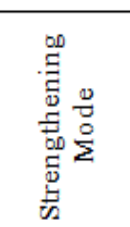 } & \multirow{2}{*}{$\begin{array}{c}\text { Transverse } \\
\text { Opening } \\
\text { Location }\end{array}$} \\
\hline & & L & W & D & & \\
\hline 1 & B-R* & \multirow{7}{*}{$\stackrel{8}{\infty}$} & \multirow{7}{*}{$\stackrel{8}{m}$} & \multirow{7}{*}{$\stackrel{\mathrm{m}}{\mathrm{m}}$} & None & None \\
\hline \multirow{3}{*}{2} & B- $0-0.5 \mathrm{~L}^{*}$ & & & & None & \multirow{3}{*}{$\mathrm{L} / 2$} \\
\hline & B-1FS-0.5L & & & & One-Face & \\
\hline & B-2FS- $0.5 \mathrm{~L}$ & & & & Two-Face & \\
\hline \multirow{3}{*}{3} & B- $0-0.25 \mathrm{~L}^{*}$ & & & & None & \multirow{3}{*}{$\mathrm{L} / 4$} \\
\hline & B-1FS- $0.25 \mathrm{~L}$ & & & & One-Face & \\
\hline & B- 2 FS $-0.25 \mathrm{~L}$ & & & & Two-Face & \\
\hline
\end{tabular}

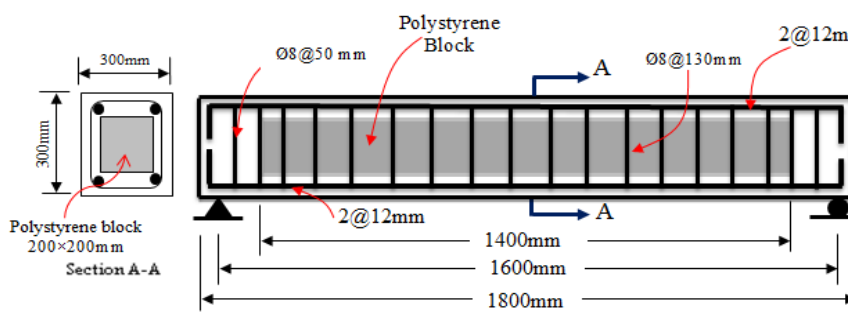

Figure 1. Details of Beam Specimen (B-R)

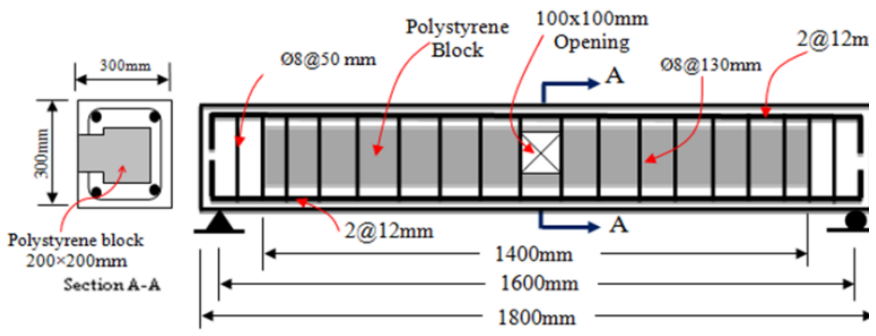

Figure 2. Details of Beam Specimen (B-0-0.5L)

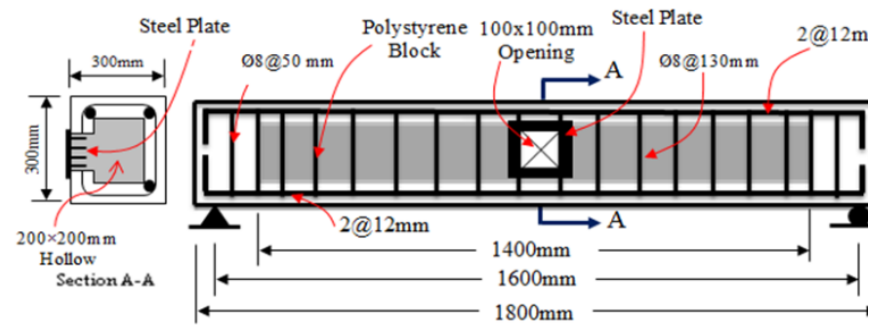

Figure 4. Details of Beam Specimen (B-1FS-0.5L)

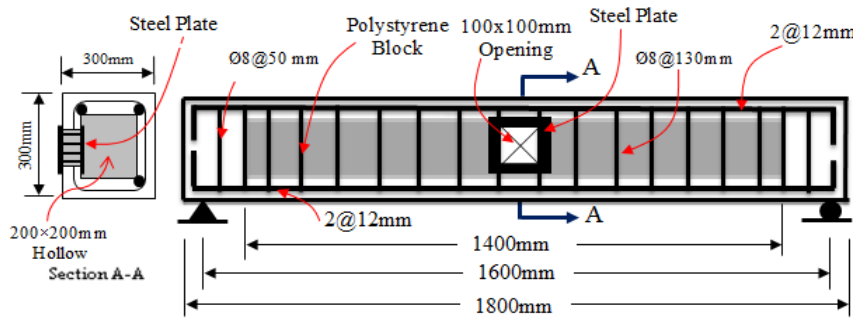

Figure 5. Details of Beam Specimen (B-2FS-0.5L)

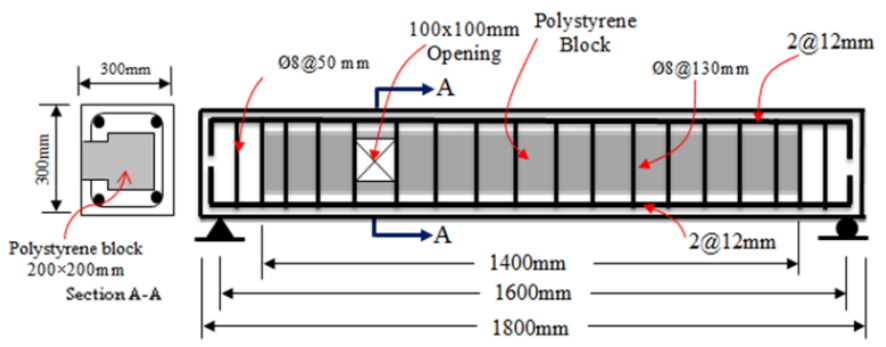

Figure 6. Details of Beam Specimen (B-0-0.25L)

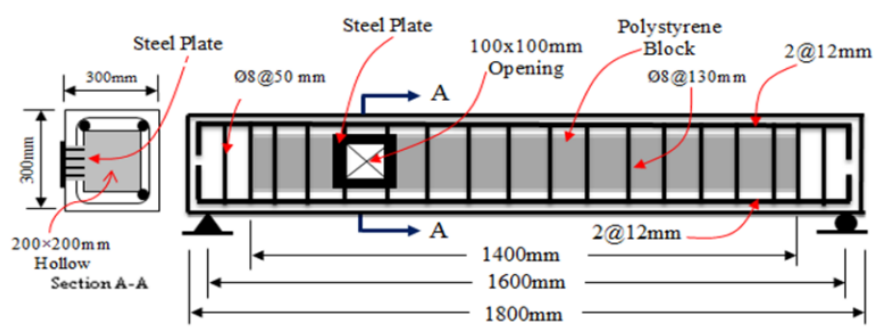

Figure 7. Details of Beam Specimen (B-1FS-0.25L)

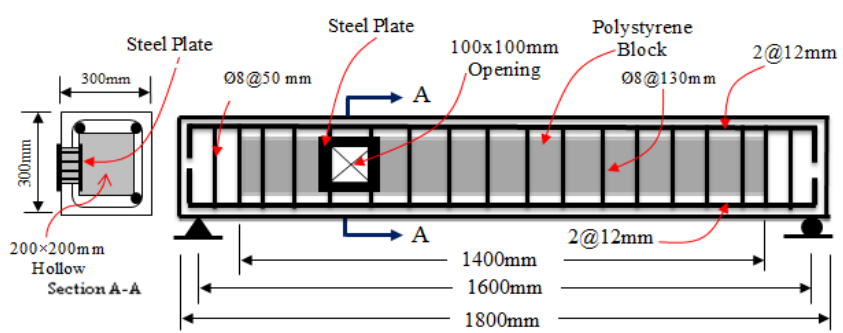

Figure 6. Details of Beam Specimen (B-2FS-0.25L) 

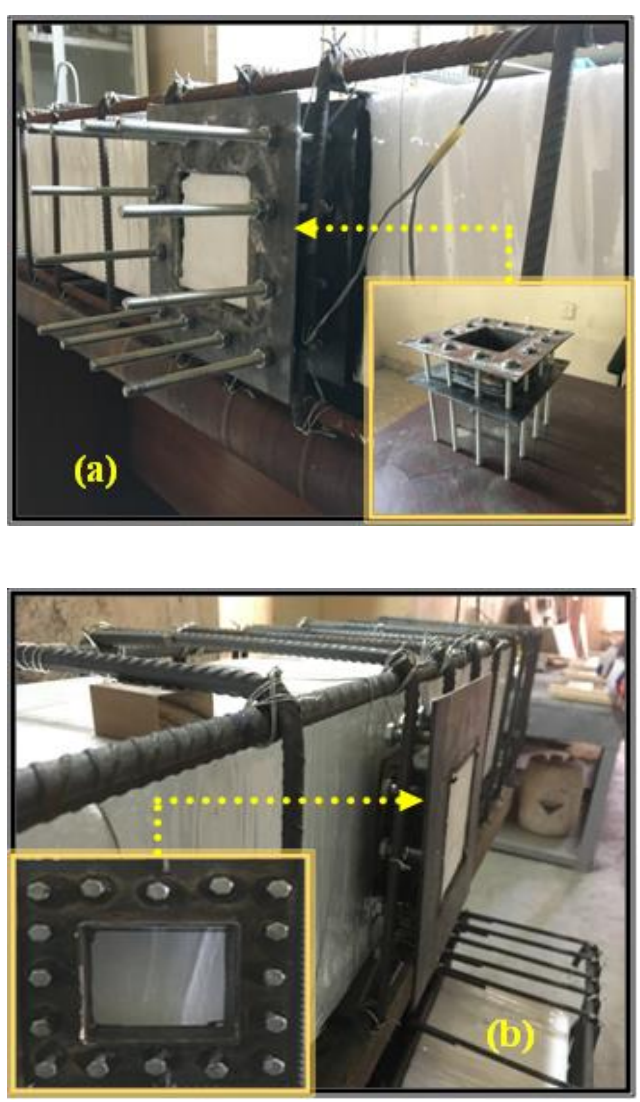

Figure 8. (a) Two-Face Localized Steel Plates. (b) OneFace Localized Steel Plates.

\subsection{Preparation and Casting of the Beam Specimens}

\subsubsection{Materials}

To create the needed test specimens, the materials that shown in Table (2) were used. To generate the longitudinal section hollowness and transverse openings, polystyrene pieces were used. Figure (9) demonstrates descriptions of longitudinal and transverse reinforcing works, localized steel plates fixing in their final locations, and polystyrene fixing in the proper position. It is worth noting that in this research, all the used materials were conforming to applicable international standards.
Table 2. Construction Material properties

\begin{tabular}{|c|c|}
\hline Material & Features description \\
\hline Cement & $\begin{array}{l}\text { Ordinary portland } \\
\text { cement(type I). }\end{array}$ \\
\hline Sand & $\begin{array}{l}\text { Natural sand passing from } \\
\text { sieve size of }(4.75 \mathrm{~mm}) \text { and } \\
\text { fine fineness modulus of } \\
(2.01) \text {. }\end{array}$ \\
\hline Gravel & $\begin{array}{l}\text { natural crushed gravel Size } \\
(12 \mathrm{~mm}) .\end{array}$ \\
\hline Limestone & Jordanian origin (Al-Gubra) \\
\hline Powder & Fine limestone powder. \\
\hline Superplasticizer & $\begin{array}{l}\text { Glenium } 51 \text { manufactured by } \\
\text { BASF construction Chemicals, } \\
\text { Jordan. }\end{array}$ \\
\hline Silica Fume & $\begin{array}{l}\text { Silica fume is a highly reactive } \\
\text { material; this type of silica } \\
\text { fume is produced by the Sika } \\
\text { company. }\end{array}$ \\
\hline Water & Clean tap water \\
\hline Steel Plate & $\begin{array}{l}\text { Steel plate with yield tensile } \\
\text { strength of }\left(f_{y}\right. \\
=507.27 \mathrm{MPa}) \text {, an ultimate } \\
\text { tensile strength of }\left(f_{u}\right. \\
=642.12 \mathrm{MPa}) \text {, and } \\
\text { elongation of }(6.14 \%) .\end{array}$ \\
\hline Reinforcing Bars & $\begin{array}{l}(\phi 8 \mathrm{~mm}) \text { deformed steel bar } \\
\text { with a yield strength of }\left(f_{y}\right. \\
=496.22 \mathrm{MPa}) \text {; and } \\
(\phi 12 \mathrm{~mm}) \text { deformed steel bar } \\
\text { with a yield strength of }\left(f_{y}\right. \\
=459.75 \mathrm{MPa}) .\end{array}$ \\
\hline
\end{tabular}



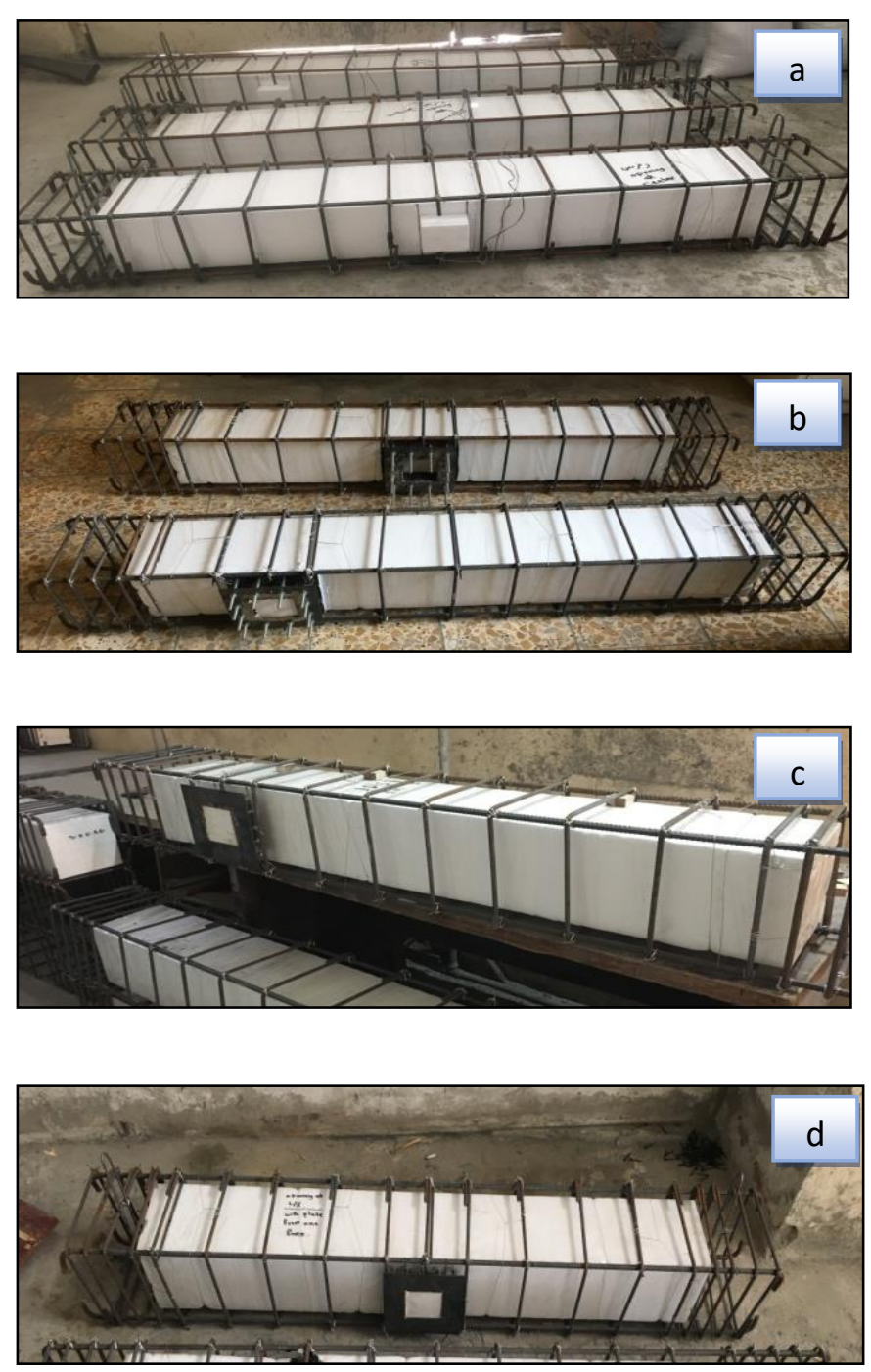

Figure 9. Details of Reinforcement, Localized Strengthening, and Polystyrene

\subsubsection{Mix and Cast of SCC}

Special mixes are required, to produce SCC, according to the mix design method of EFNARC [13] and the procedures adopted by the other researchers. The used materials of SCC are similar to those in conventional concrete but with some modification. The proportions of SCC mixes (by weight) are listed and given in Table (3). The rotating mixer has been used to mix the raw materials and to manufacture the SCC for all beam and control specimens. To cast the beam specimens, four wooden molds of $(18 \mathrm{~mm})$ thickness are used; the wooden molds had a base and four sides; these four sides had been fixed with the base by screw bolts. The mold 's internal dimensions (1800x300x300 mm) are respectively for the length, width, and height. Oil was used to cast into the mold and mandatory reinforcement cages which were positioned in the mold before the concrete batch was cast. Figure (10) shows the concrete mixer and details of the wooden mold.

Table 3. Proportions of $\left(1 \mathrm{~m}^{3}\right)$ of SCC Mixture

\begin{tabular}{|c|c|}
\hline Cement. & $500 \mathrm{~kg}$ \\
\hline Sand. & $750 \mathrm{~kg}$ \\
\hline Gravel. & $900 \mathrm{~kg}$ \\
\hline Limestone & $130 \mathrm{~kg}$ \\
\hline Silica fume & $30 \mathrm{~kg}$ \\
\hline Water & $150 \mathrm{Liter}$ \\
\hline Super Plasticizer & $10 \mathrm{Liter}$ \\
\hline
\end{tabular}
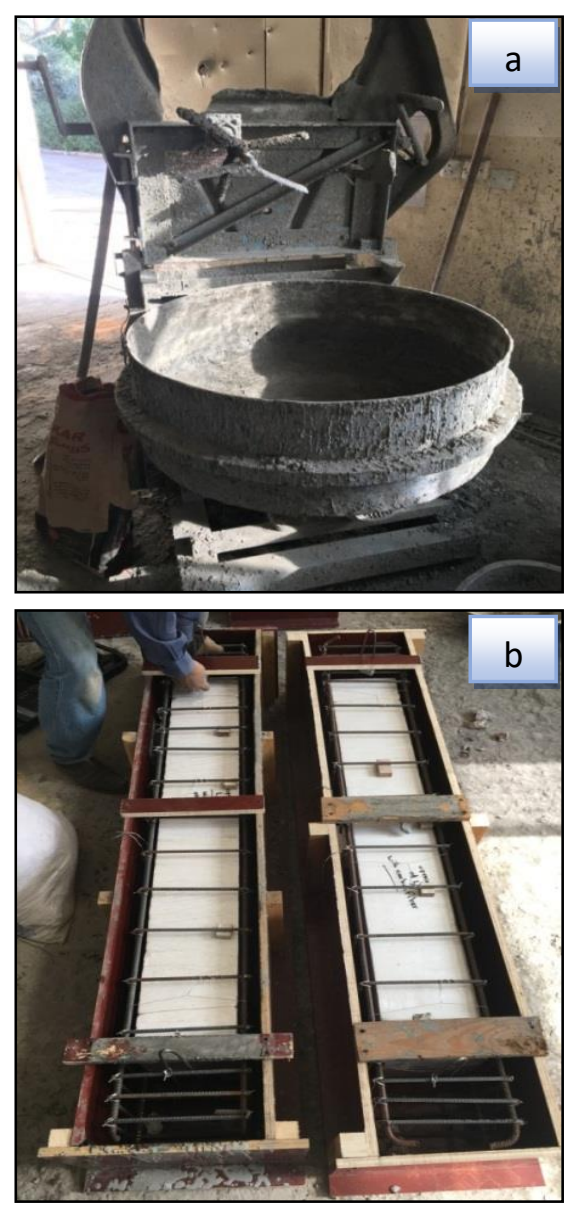

Figure 10. Concrete Mixer and Details of the Wooden Molds 


\section{Instrumentation, measurements, and test procedure.}

\subsection{Instrumentation and measurements.}

The beam specimens were tested using a hydraulic universal test machine for cracking and ultimate torques (produced by, Maschinen Fabrik. Liezen, MFL) with a maximum loading capacity of (3000 $\mathrm{kN})$. The supports of this machine can remain fixed or hinged from one side or both, and it have been designed to be able to rotate about a longitudinal axis of the beam to allow free application of torsion, as shown in figure (11). The angle of twist was measured at both ends of the beam specimen using two dial gauges attached to the bottom fibers at $(100 \mathrm{~mm})$ distance of the longitudinal center for each end; vertical deflection was recorded to calculate the twist angle with radians at each load stage. The method used to calculate the longitudinal elongation represented by using two dial gauges attached at the center of the edges faces (the side fiber of the ends of the beam) as illustrated in Figure (12). Strain gages were used to determine the deformation of steel reinforcements, localized steel plates, and concrete when the load is applied. Strain gauges type (PL-60-11), produced by TML Company, were used to measure the strains in steel reinforcements, localized steel plates, and concrete. To transfer the electrical signals to corresponding strains, data logger type (TML/ TC-32K) was used. It may be noted that the strain gauges are fixed in six different locations as shown in Figure (13) and Table (4).

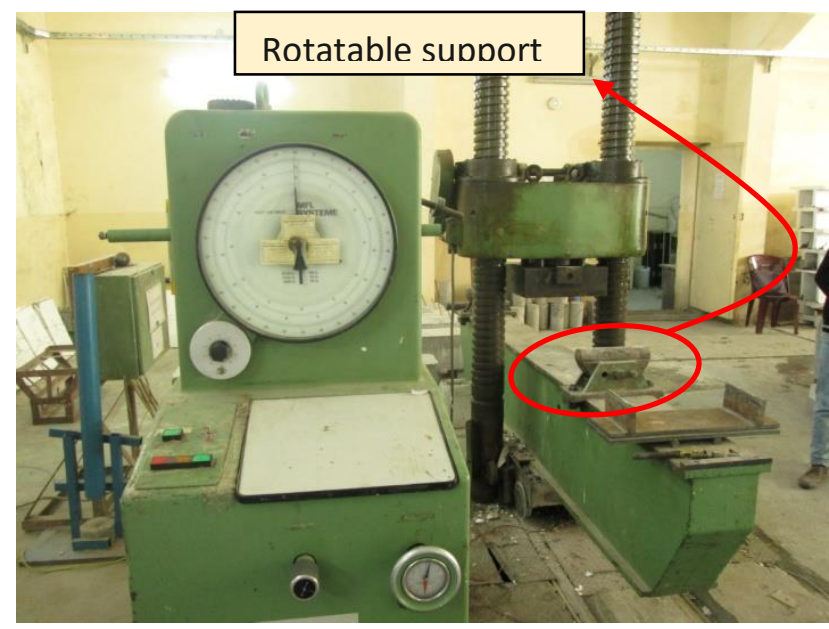

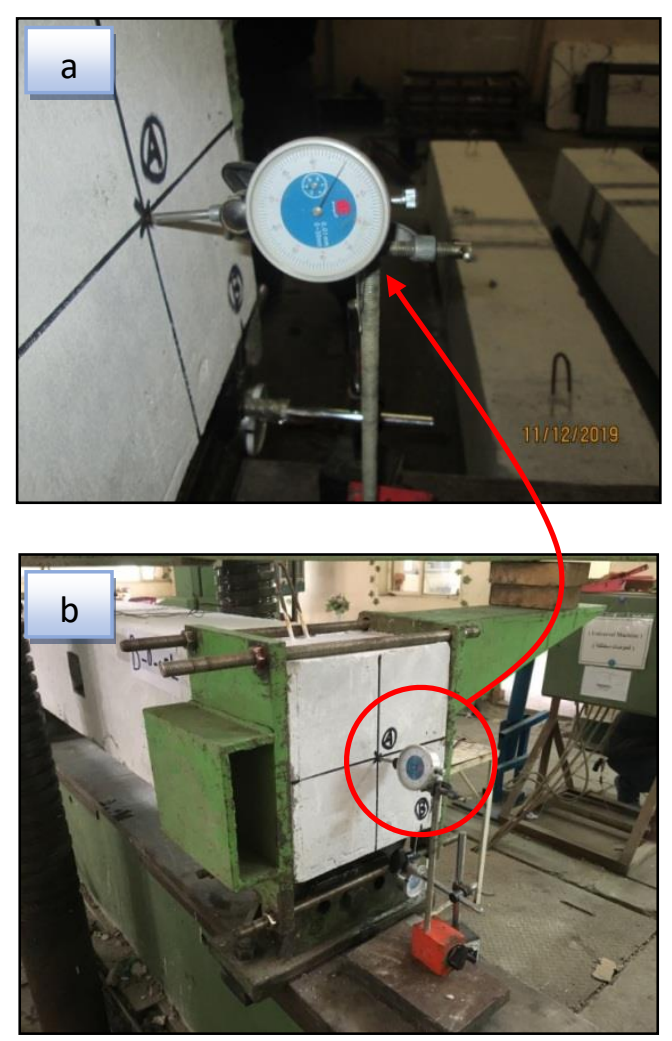

Figure 12. Locations of Dial Gauges
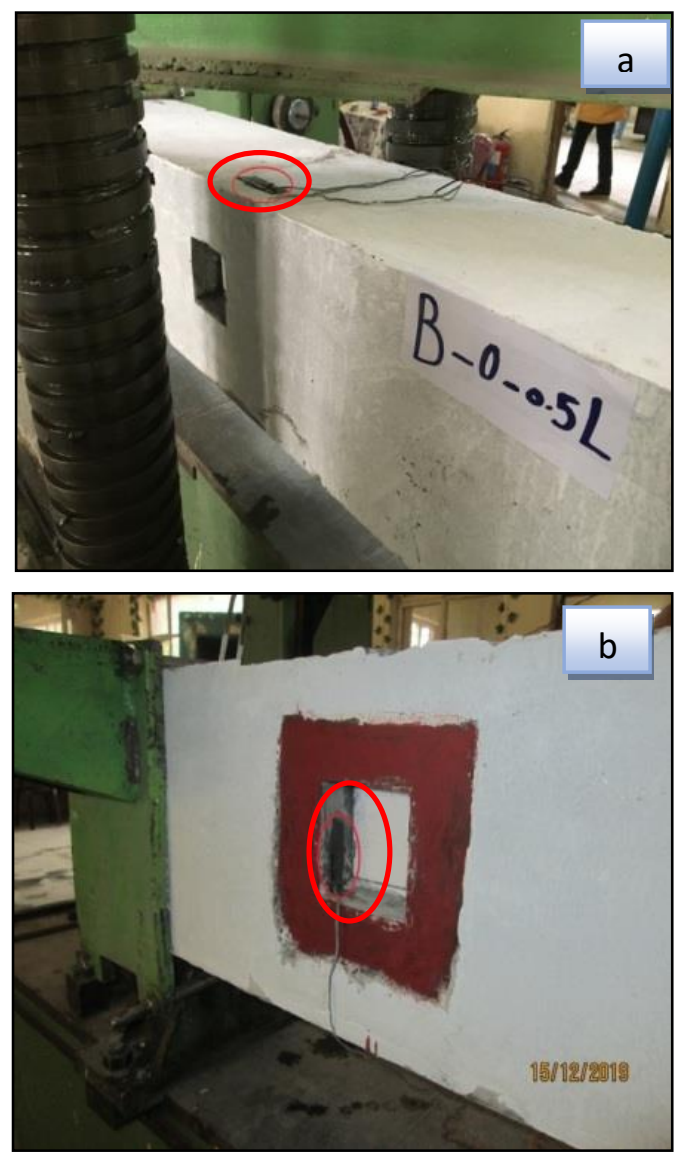

Figure 11. Hydraulic universal test machine 


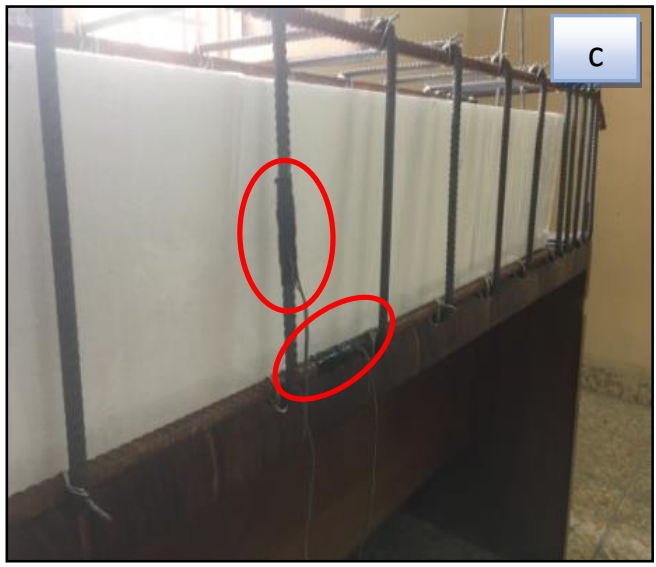

Figure 13. Strain Gauges in Concrete, Localized Steel Plates, and steel Bars

Table 4. Locations of the Strain Gauges

\begin{tabular}{|c|l|}
\hline Gauge No. & \multicolumn{1}{|c|}{ Location } \\
\hline 1 & At Stirrup (Mid-Span) \\
\hline 2 & At Longitudinal Steel Bars (Mid-Span) \\
\hline 3 & $\begin{array}{l}\text { At Steel plate that lining transverse } \\
\text { opening (At vertical side) }\end{array}$ \\
\hline 4 & $\begin{array}{l}\text { At the top face of Beam (concrete), } \\
\text { (Mid-Span) }\end{array}$ \\
\hline
\end{tabular}

\subsection{Procedure of The Test}

Figure (14) illustrates the test setup of the tested beam specimens. The tested Beam specimen can be installed on machine supports that can be set to rotate, so the tested specimen will rotate around its longitudinal axis freely at the ends. The load is applied to the middle of the large flange steel beam then equally converts it to the loading arms as two focused loads at a distance $(500 \mathrm{~mm})$ from the axial axis of beam specimens being examined. These eccentrics distances at the ends of the tested specimen are needed to achieve a torsional mechanism by passing the load to the arms as a concentrated torque at the ends of the specimen and a concentrated vertical force transmitted directly to the supports. Applied loads were recorded with first observable crack (Pcr) as well as at the final failure $(\mathrm{Pu})$, it is worth noting that the first crack took place when the specimen approached the yield load. It is obvious that this placement is symmetrical about the mid-span of the specimen except (T) has an opposite sense at the ends.

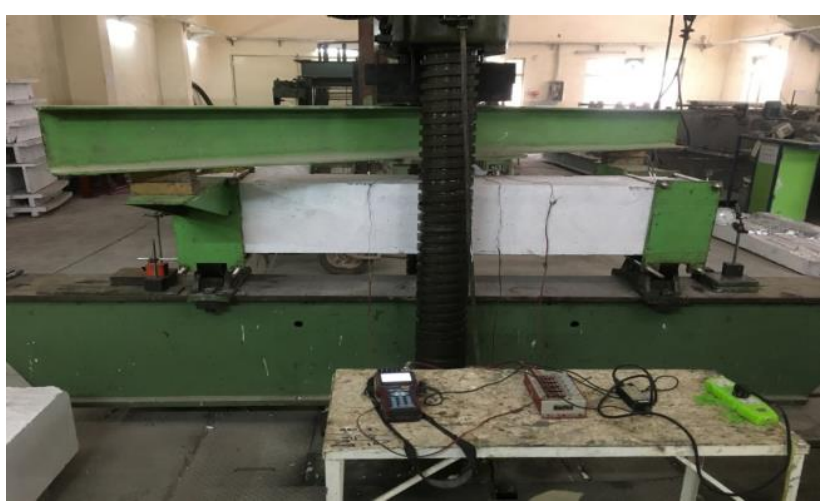

Figure 14. Beam Specimen Setup and Loading Arrangement

\section{SCC Properties}

\subsection{Tests of Fresh SCC Control}

There have been ten various tests according to EFNARC[13] standards to guarantee that the manufactured concrete is of an SCC type. Not all of these ten tests need to be carried out on fresh SCC; Therefore in the present research, three tests have been adopted as control tests on fresh SCC, namely (V- funnel, L- box, and slump flow) tests, such three tests indicated fresh SCC properties, particularly the important three characteristics of the SCC, ability to fill, ability to pass, and resistance to segregation. The findings of the tests showed that the SCC used conforms to EFNARC requirements [13].

\subsection{Hardened SCC Control Tests}

A sequence of tests to determine the mechanical properties of hardened SCC were conducted; The compressive strength tests were performed on cubic specimens and standard cylindrical based on the basic requirements of BS 1881-116 1983[16], and ASTM C39M-01[15] respectively. The concrete splitting strength test (Indirect Tensile Strength) was performed on the standard cylindrical specimens according to ASTM C496-96 [17]. To evaluate the rupture modulus of the SCC, prisms (simple beams) of $(500 \times 100 \times 100 \mathrm{~mm})$ dimensions were tested under the effect of 2-point concentrated loading. Finally, the concrete elasticity modulus test has been conducted according to ASTM C469-02 [18] using the standard cylindrical specimens. It may be noted that all control specimen tests were conducted at the age of (28days). Table (5) shows a summary of the result of the tests. 
Table 5. Summary of Hardened SCC Testes Results

\begin{tabular}{|c|c|c|c|c|}
\hline \multicolumn{2}{|c|}{$\begin{array}{c}\text { Compressive Strength } \\
(\mathrm{MPa})\end{array}$} & $f_{r}$ & $f_{t}$ & $E_{c}$ \\
$(\mathrm{MPa})$ & $(\mathrm{MPa})$ & $(\mathrm{MPa})$ \\
\cline { 1 - 4 }$f^{\prime}{ }_{c}$ & $f_{c u}$ & & & \\
\hline 50 & 58.8 & 3.6 & 3.2 & 30376 \\
\hline
\end{tabular}

\section{Evaluation and discussion of the test results}

\subsection{Overall behavior}

Experimental results are summarized and provided in Table (6). At the beginning of loading the reference beam without transverse opening twisted without any cracks. The first cracks appeared at the midpoint of the vertical faces at the mid-span of the beam, it is worth noting that the first crack took place when the specimen approached the yield load. As the applied load increases, the torsional diagonal cracks, at an inclination of about $\left(45^{\circ}\right)$ to the horizontal axis, propagate towards the horizontal face of the beam soon subsequently around all faces of the beam forming continuous helical cracks and the beam failed due to excessive increase of diagonal cracks at the mid-span of the beam. At failure, extensive parallel cracks on each side along the span of the beam were observed. For beams containing transverse opening without strengthening. As the opening represents a source of weakness, the initial crack originates at the corners of the opening at the tension side and propagate diagonally, at an inclination about $\left(45^{\circ}\right)$, towards outside the opening zone of the beam. As the applied torque was increased, discrete small diagonal cracks appeared distributed on the part outside the opening zone and a diagonal crack links the two opposite compression faces of the top chord has been formed which led to the failure of the beam. Before the failure, a voice of cracking of concrete was heard. For beams containing transverse opening with strengthening by localized steel plates, the failure was observed outside the opening zone as a result of the existing these strengthen. This strengthens curb the excessive diagonal tension and decreased the spread of the cracks from corners and transfer the failure to be outside the opening zone, this was combined with the ability of steel reinforcement to sustain larger tensile stresses at advanced stages of loading. So the initial cracks originate in the middle of the deeper face of the beam and crawled towards the opening corner. Before the failure, a voice from cracking of concrete and deboning of fiber was heard. The crack pattern and mode of failure are shown in Figure (15).

Table 6. Cracking and Ultimate Torque for Beams

\begin{tabular}{|c|c|c|c|c|c|c|}
\hline 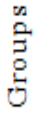 & $\begin{array}{l}\text { Designation of } \\
\text { the Beams }\end{array}$ & $\begin{array}{c}\text { Pcr } \\
(\mathrm{kN})\end{array}$ & $\begin{array}{c}\mathrm{Pu} \\
(\mathrm{kN})\end{array}$ & $\begin{array}{l}\mathrm{Tcr} * * \\
(\mathrm{kN} . \mathrm{m})\end{array}$ & $\begin{array}{l}\mathrm{Tu}^{* *} \\
(\mathrm{kN.m})\end{array}$ & $\begin{array}{c}(\mathrm{Tcr} / \mathrm{Tu}) \\
\%\end{array}$ \\
\hline 1 & B-R* & 110.0 & 160.0 & 27.50 & 40.00 & 68.75 \\
\hline \multirow{3}{*}{2} & B- $0-0.5 \mathrm{~L}^{*}$ & 60.0 & 87.5 & 15.00 & 21.88 & 68.57 \\
\hline & B-1FS-0.5L & 62.5 & 105.0 & 15.63 & 26.25 & 59.52 \\
\hline & B-2FS-0.5L & 77.5 & 108.5 & 19.38 & 27.13 & 71.43 \\
\hline \multirow{3}{*}{3} & B- $0-0.25 \mathrm{~L}^{*}$ & 77.5 & 104.5 & 19.38 & 26.13 & 74.16 \\
\hline & B-1FS- $0.25 \mathrm{~L}$ & 85.0 & 140.0 & 21.25 & 35.00 & 60.71 \\
\hline & B-2FS- $0.25 \mathrm{~L}$ & 102.5 & 162.5 & 25.63 & 40.63 & 63.08 \\
\hline
\end{tabular}

*Reference beams $* * \mathrm{~T}=(\mathrm{P} / 2) *$ Arm, and $\operatorname{Arm}=0.5 \mathrm{~m}$

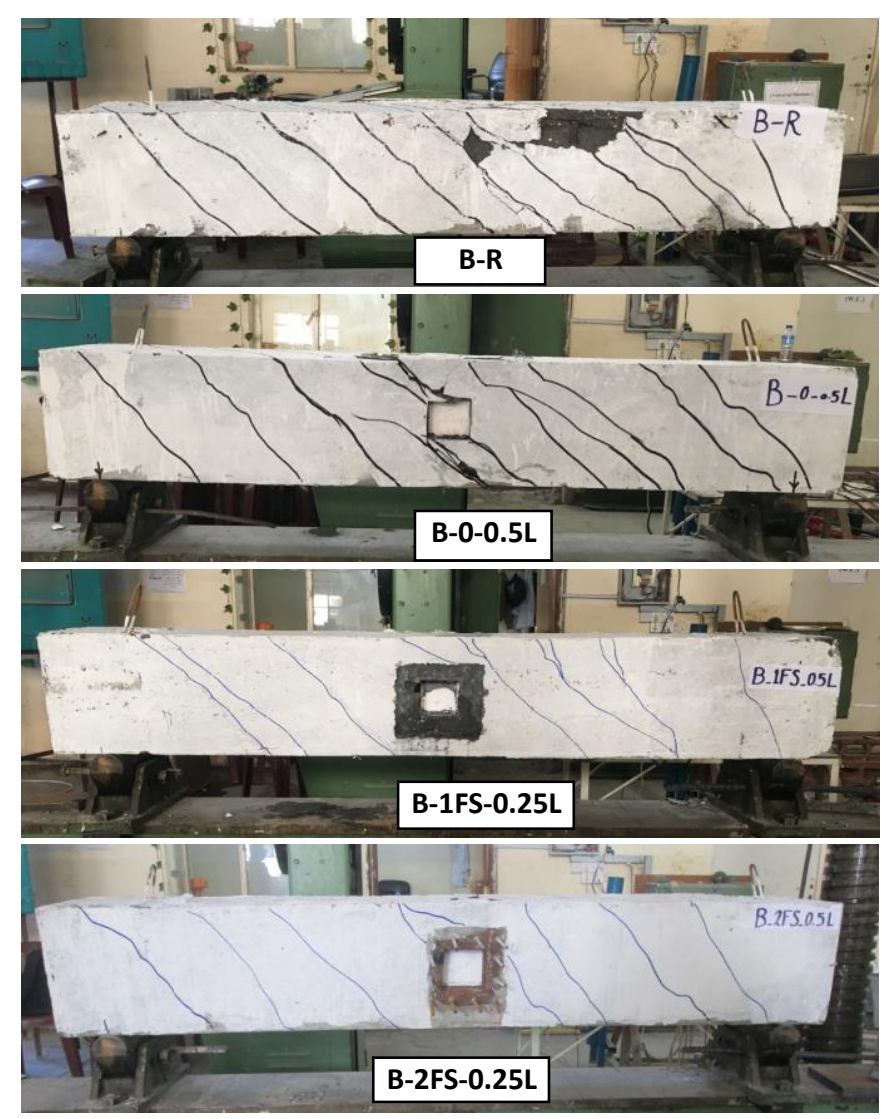




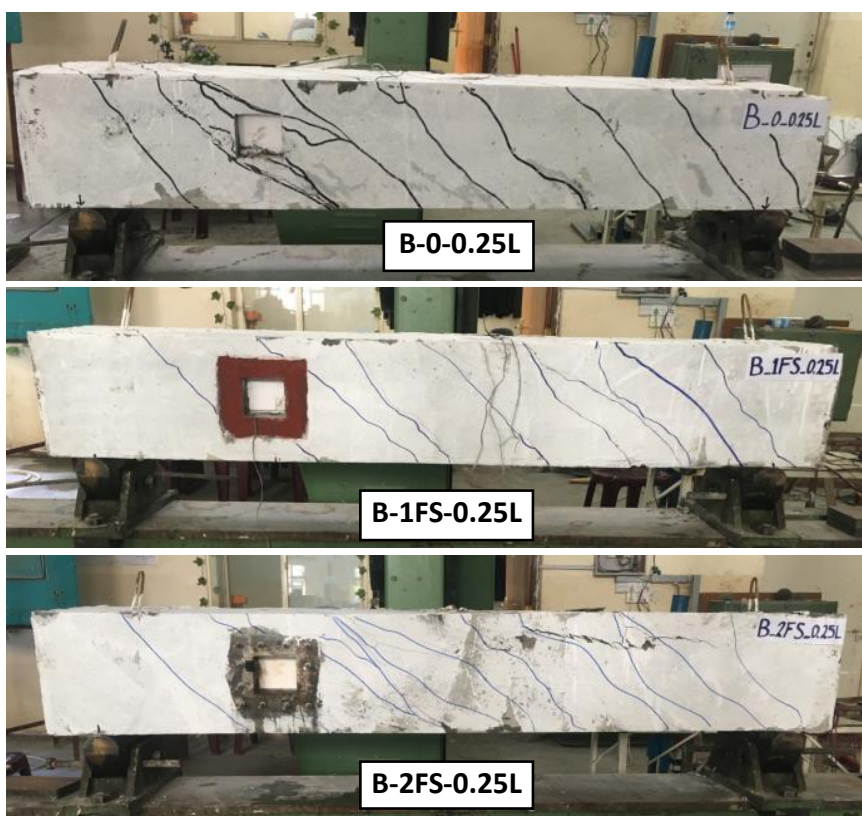

Figure 15. Crack Pattern after Failure

\subsection{Torque at cracking and peak (ultimate) state}

The cracking and final moment values of all tested beams were calculated and given in table (7). And the patterns of the cracks for the beams being studied are illustrated in Figure(15). For the three references tested beams, It can be observed that the existence of the transverse opening in a quarter of the clear distance $(\mathrm{L} / 4)$ of the concrete hollow beam (B-0-0.25L) and the middle of the clear distance $(\mathrm{L} / 2)$ of the concrete hollow beam (B-0-0.5L) decreases the cracking torque by about $(29.54 \%$ and $45.4 \%$ ) respectively, relative to the other reference beam (B-R) that does not contain transverse opening. On the other hand, for group two, relative to the reference beam $(\mathrm{B}-0-0.5 \mathrm{~L})$, it can be seen that for beam specimens (B-1FS-0.5L and B-2FS-0.5L) the cracking torque moment increases by about $(4.16 \%$ and $29.16 \%)$ respectively. While, for the third group, relative to the tested reference beam (B$0-0.25 \mathrm{~L}$ ), it could be seen that for beam specimens (B-1FS-0.25L and B-2FS-0.25L) the cracking torque moment increases by about $(9.68 \%$ and $32.25 \%)$ respectively. It can be inferred that the presence of localized reinforcement improves the torsional resistance and this enables the transmission of higher forces through the localized steel plate.
As for the ultimate torque capacity, for the three reference beams tested, it can be found that the presence of the transverse opening at a quarter of the clear distance $(\mathrm{L} / 4)$ of the concrete hollow beam (B$0-0.25 \mathrm{~L})$ and at the center of the clear distance $(\mathrm{L} / 2)$ of the concrete hollow beam (B-0-0.5L) decreases the ultimate torque efficiency respectively by approximately (34.7\% and $45.3 \%$ ), compared to the other control beam (B-R). On the other hand, for the second group, relative to the control beam (B-0$0.5 \mathrm{~L}$ ), It can also be noticed, that the capacity of the maximum torque increases at around (20\% and 24\%). for beam specimens (B-1FS-0.5L and B-2FS$0.5 \mathrm{~L})$ respectively. While, For the third group, relative to the control beam (B-0-0.25L), it could be noticed, that the cracking torque increases by around (34\% and 55.5\%), for beam specimens (B-1FS$0.25 \mathrm{~L}$ and $\mathrm{B}-2 \mathrm{FS}-0.25 \mathrm{~L})$ respectively. It can be concluded, that beam specimens with a two-face localized steel plate have the highest torsional capacity, and there has been no separation between concrete and steel plates. The presence of localized steel plate allows carrying higher forces (in-plane and out of-plane) directions, due to the contribution of the localized strengthening, and this leads to increase the beam section efficiency and improves the torsional resistive capacity. Figure (16). shows the effect of the existence of transverse opening and localized strengthening on the cracking and ultimate torques.

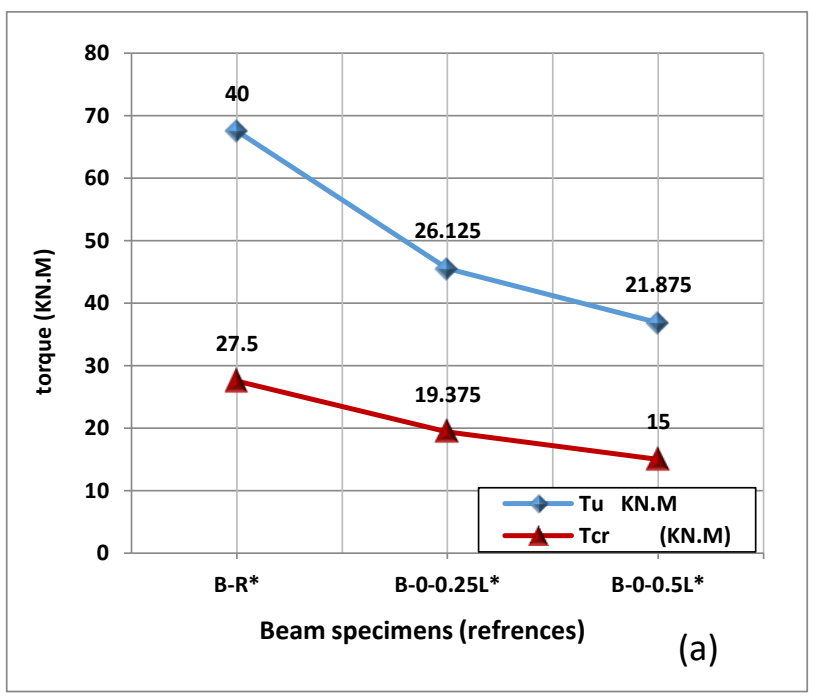



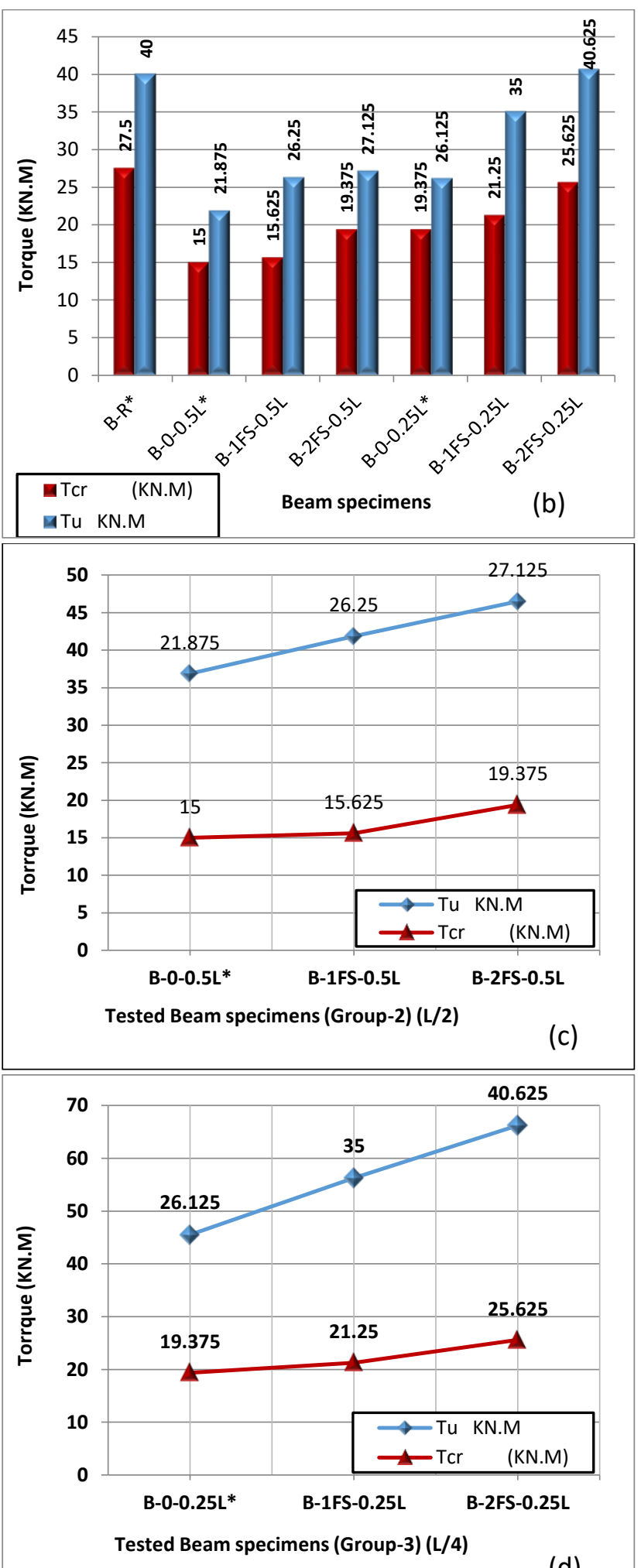

(d)

Figure 16. (a) Effect of web openings on crack and ultimate torque (b) ultimate and cracking torque for all beams, (c) Effect of strengthening on cracking and ultimate torque (Group-2), (d) Effect of strengthening on cracking and ultimate torque(Group-3).

\subsection{Torsion-angle of twist response}

Figure (17) showed the relation of the angle of a twist to torque in all beams ( $\mathrm{T}-\theta$ Diagram), which was taken from the measured obtained results during the test run in each beam specimen exam. The twist angle for reference beam specimens (B-0-0.5L) and (B-0-0.25L) are increased by about $(97 \%)$ and $(69.3$ $\%)$ respectively, relative to other reference beam specimens (B -R). On the other hand, in group two, the Maximum angle of twist of the specimens (B1FS-0.5L) and (B-2FS-0.5L) are decreased by around $(20 \%)$ and (38 \%) respectively, in comparison with the reference specimen (B-0-0.5L). Whereas in group three, the maximum angle of twist of specimens (B-1FS-0.25L) and (B-2FS-0.25L) is decreased by around (25.6\%) and (40.4\%) respectively, in comparison with the reference specimen ( B-0-0.25L).

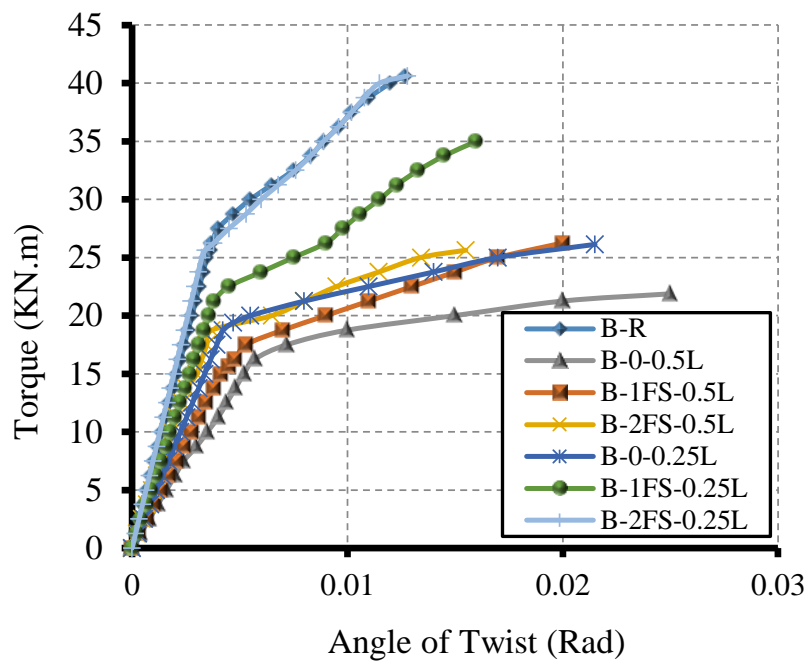

Figure 17. Torque-angle of twist response for tested beam specimens.

\subsection{Torsion-longitudinal elongation response}

At the first stage of loading, the concrete skin alone carried all the applied load and no longitudinal elongation was recorded in beam specimens, even cracking loads (When the tensile stresses exceed the concrete's tensile strength), and the warping gradually increased in a nonlinear manner (due to the behavior of longitudinal steel reinforcement and its ability to sustain greater tensile stresses at 
advanced stages of loading) up to the failure, Figure (18), this state is produced because the shear strain varying around the section's circumference, causing the section deformation in such a manner (the plane sections through the beams do not remain plane).

For reference beams (B-0-0.5L) and (B-0-0.25L), the longitudinal elongation increased by about $(51.56 \%)$ and $(35.5 \%)$ respectively, compared to the control beam, (B -R), this due to the presence of a transverse opening which leads to an excessive increase in cracks width that occurs in the beam specimens especially at the corners of the transverse opening and as a result, the cumulative longitudinal elongation increase. From the other hand, for strengthening tested beams of the second group, compared to the same level of the control beam specimen (B-0-0.5L), the elongation in the longitudinal axis of the tested beams (B-1FS-0.5L) and (B-2FS-0.5L) were generally decreased by about (47\% and $73 \%)$ respectively. While, for the strengthened tested beams of the third group, comparison to the same level of the control beam specimen (B-0-0.25), the elongation in the longitudinal axis of the tested beams (B-1FS-0.25L) and (B-2FS-0.25L) were generally decreased by about $(91.4 \%$ and $96.2 \%)$ respectively.

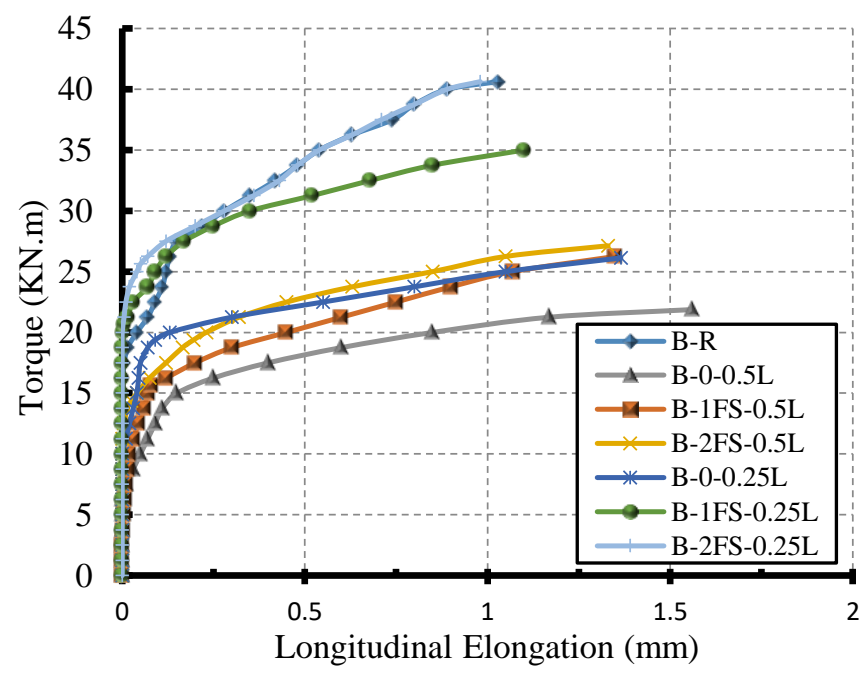

Figure 18. Torque-warping Relationship for Tested Beam Specimens

\subsection{Reinforcing steel bars strains}

\subsubsection{Longitudinal reinforcement strains}

As already stated, the strains in longitudinal steel bars were measured at beam specimens' mid-span. The torque variance and related longitudinal reinforcement strains are plotted and shown in Figure (19).

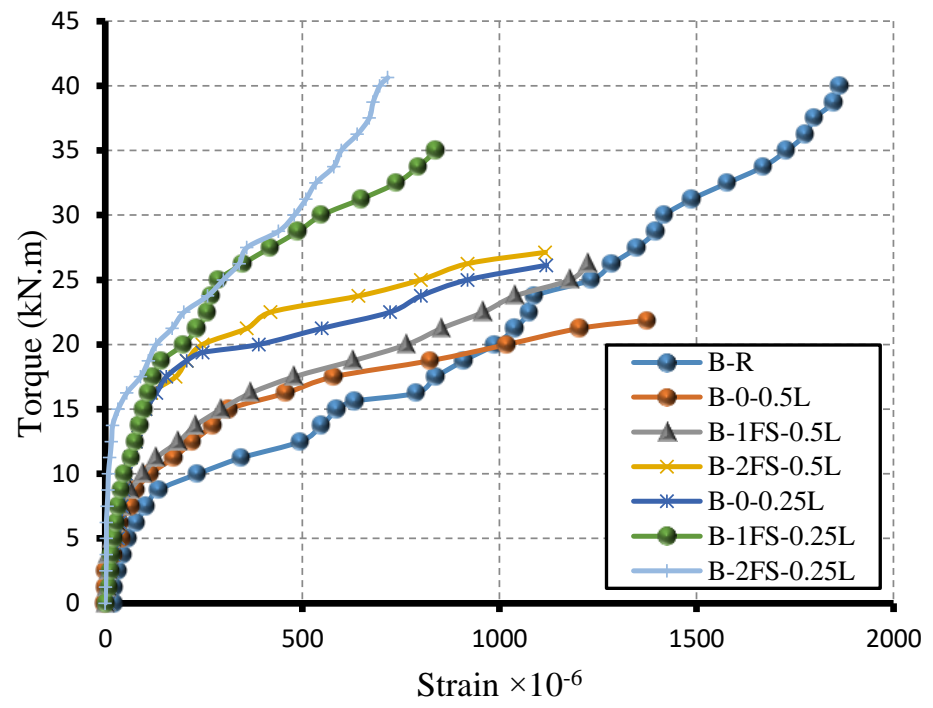

Figure 19. Torque-Strain Relationship for Longitudinal Bars

Before the initial crack, all tested beams respond in a linear manner and there had been noticeable disturbances overall beam specimens for strain values beyond this point. At the ultimate stages, for all the tested beam specimens, all strain values were positive (Tension). The ultimate strain of the control specimen (B-R) for the longitudinal steel bars is equal to $\left(1865 \times 10^{-6}\right)$. While, for group two the maximum strains of the longitudinal steel bars of beam specimens $(\mathrm{B}-0-0.5 \mathrm{~L}),(\mathrm{B}-1 \mathrm{FS}-0.5 \mathrm{~L})$, and $(\mathrm{B}-$ $2 \mathrm{FS}-0.5 \mathrm{~L})$ were equal to $\left(1377 \times 10^{-6}, 1226 \times 10^{-6}\right.$, and $1117 \times 10^{-6}$ ) respectively. On the other hand, for group three the maximum strains for the longitudinal steel bars of beam specimens (B-0-0.25L), (B-1FS$0.25 \mathrm{~L})$, and $(\mathrm{B}-2 \mathrm{FS}-0.25 \mathrm{~L})$ are equal to $\left(1120 \times 10^{-6}\right.$, $840 \times 10^{-6}$, and $717 \times 10^{-6}$ ) respectively. It can be inferred that the longitudinal bar strain of the reference beams (B-R), (B-0-0.5L) in group two and (B-0-0.25L) in group three represents the largest values, but does not surpass the theoretical yield strain value of $\left(\varepsilon y=2300 \times 10^{-6}\right)$. Likewise, all the rest other beam specimens do not reach its yield point 
strain; that does say the longitudinal rebar of these beam specimens can carry additional torsional moment beyond the recorded maximum strain.

\subsubsection{Transverse Reinforcement (Stirrups) Strains}

As mentioned earlier, the strains were measured at the tested beam specimens' mid-span in steel stirrups (T- $\varepsilon_{\mathrm{st}}$ ). The variation of the torque and the corresponding steel stirrups strains are plotted and provided in Figure (20). At the ultimate stages, For all the tested beam specimens, all strain values were positive (Tension). The ultimate strain for the longitudinal steel bars of the control specimen (B R) equal to $\left(1450 \times 10^{-6}\right)$. While, for group two the maximum strains of steel stirrups of beam specimens (B-0-0.5L), (B-1FS-0.5L) and (B-2FS-0.5L) were equal to $\left(2238 \times 10^{-6}, 468 \times 10^{-6}\right.$, and $\left.712 \times 10^{-6}\right)$ respectively. On the other hand, for group three the maximum strains for the steel stirrups of beam specimens (B-0-0.25L), (B-1FS-0.25L), and (B-2FS$0.25 \mathrm{~L})$ were equal to $\left(1972 \times 10^{-6}, 1560 \times 10^{-6}\right.$, and $\left.1436 \times 10^{-6}\right)$ respectively. It concluded that strain in steel stirrups of the reference beam specimens (B-0$0.5 \mathrm{~L})$ in group two and $(\mathrm{B}-0-0.25 \mathrm{~L})$ in group three, represents the largest values and but not exceeds the yielding value, that does say, it nearby to amount to yield point strain before the other specimens, in compared to theoretically calculated yield strain value of $\left(\varepsilon y=2481 \times 10^{-6}\right)$. Likewise, all the rest other beam specimens do not reach it yield strain; this means the steel stirrups of these beam specimens can carry additional torsional moment beyond the recorded maximum strain.

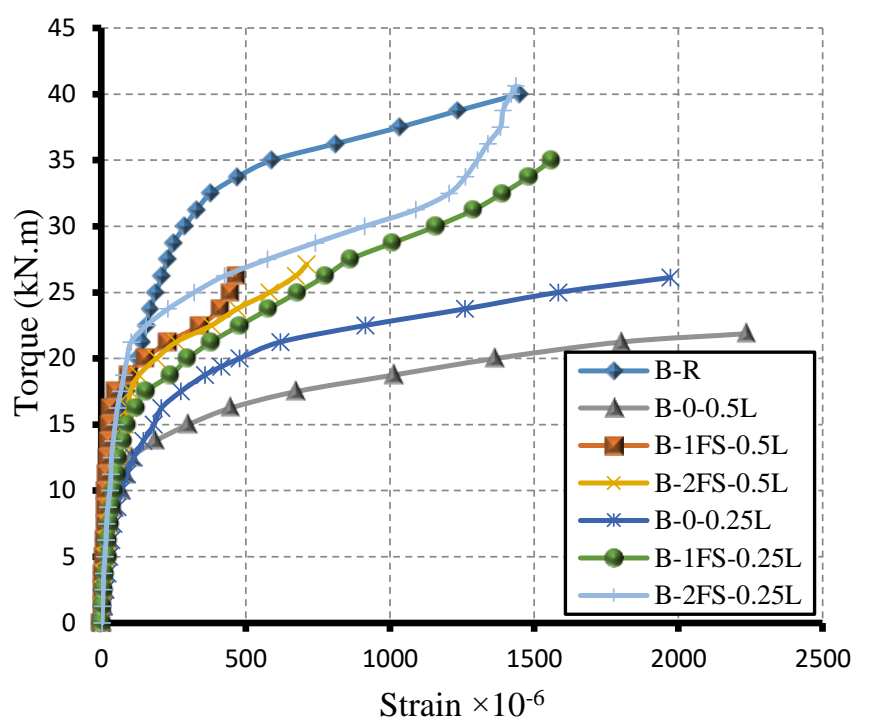

Figure 20. Torque-strain relationship for stirrups

\subsubsection{Strains in Concrete}

Varying of torque with the concrete strain $\left(T-\varepsilon_{c}\right)$ is evaluated in the outer side of the top skin at beams' mid-span. In this research, the strain's values were measured at each $(5 \mathrm{kN})$. With a diagonal concrete crack, all beam specimens fail (Torsional Spiral Cracks), this means that the torque stress exceeds the torque capacity of concrete and the specimens are approaching the peak point of response. All concrete strain values are negative (compression), as illustrated in Figure(21). The maximum concrete strain of testing control beam specimen (B-R) is equal to $\left(-680 \times 10^{-6}\right)$. While, for group two the maximum strains in the concrete of beam specimens (B-0-0.5L), (B-1FS-0.5L), and (B-2FS-0.5L) were equal to $\left(-631 \times 10^{-6},-410 \times 10^{-6}\right.$ and $\left.-368 \times 10^{-6}\right)$ respectively. From the other hand, for group three the maximum strains in concrete of beam specimens (B-0-0.25L), (B-1FS-0.25L) and (B-2FS-0.25L) are equal to $\left(-560 \times 10^{-6},-432 \times 10^{-6}\right.$ and $\left.-5562 \times 10^{-6}\right)$ respectively. It may be concluded that the presence of a transverse opening as a source of weakness and localized steel plate strengthening for these beams, leads to a redistribution of the stresses that result from the torsional moments in the concrete skin along the tested beams. 


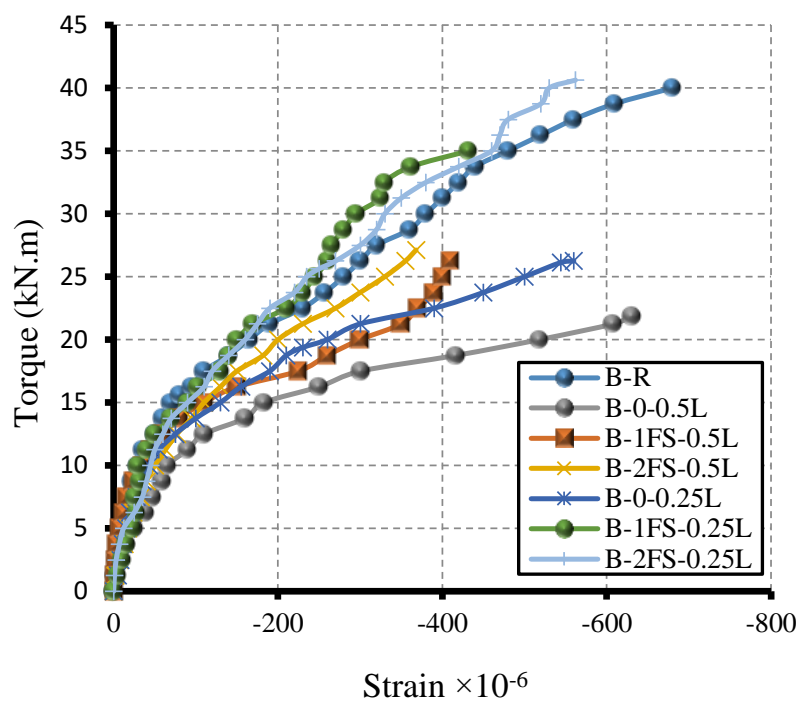

Figure 21. Torque-strain relationship for concrete

\subsubsection{Localized Steel plate Strains $\left(\varepsilon_{s p}\right)$}

The variation of the strain of localized steel plate with torque (T- $\varepsilon_{\mathrm{sp}}$ ) was measured in each localized steel plate by using strain gauge placed (attached) in position (in the inner vertical lining of the localized steel plate), as shown in Figure (13). As represented in Figure (22), in group two, for beam specimen (B1FS-0.5L) that contain one side of steel plate as a localized strengthening, the maximum measured strain was equal to $\left(196 \times 10^{-6}\right)$, while for beam specimen (B-2FS-0.5L) that contain two sides of steel plate as a localized strengthening, the maximum measured strain was equal to $\left(201 \times 10^{-6}\right)$.

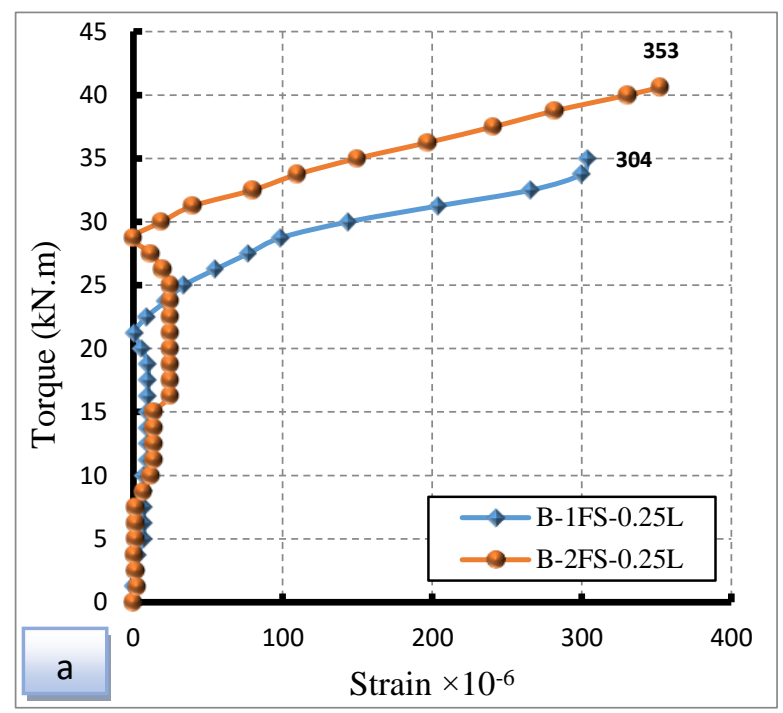

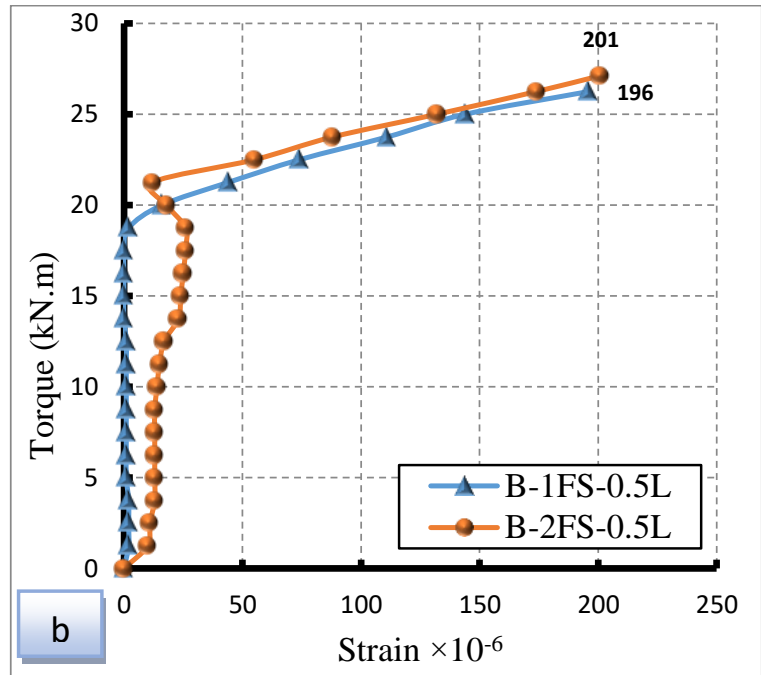

Figure 22. Torque-Strain Relationship for Localized Steel plates

On the other hand in group three, for beam specimen (B-1FS-0.25L) that containing one side of steel plate as a localized strengthening, the maximum measured strain was equal to $\left(304 \times 10^{-6}\right)$, while for beam specimen (B-2FS-0.25L) that contain two sides of steel plate as a localized strengthening, the maximum measured strain was equal to $\left(353 \times 10^{-6}\right)$ that represents the highest reported value. It might be reached the conclusion that all strain values have been positive, also all the localized steel plate didn't reaching the yielding value of the theoretical yield strain of steel plate $\left(\varepsilon y=2535^{*} 10^{-6}\right)$; which means the ability of localized steel plate to undergo (carry) addition torsional moment. Figure (23), shows the visible deformation for bolts of localized steel plate after testing. Clearly, there is major damage in welding (separation) at the base of bolts; this may be due to high shear flow, which produced due to torsion stresses, inside the vertical concrete skin of the box beams. 

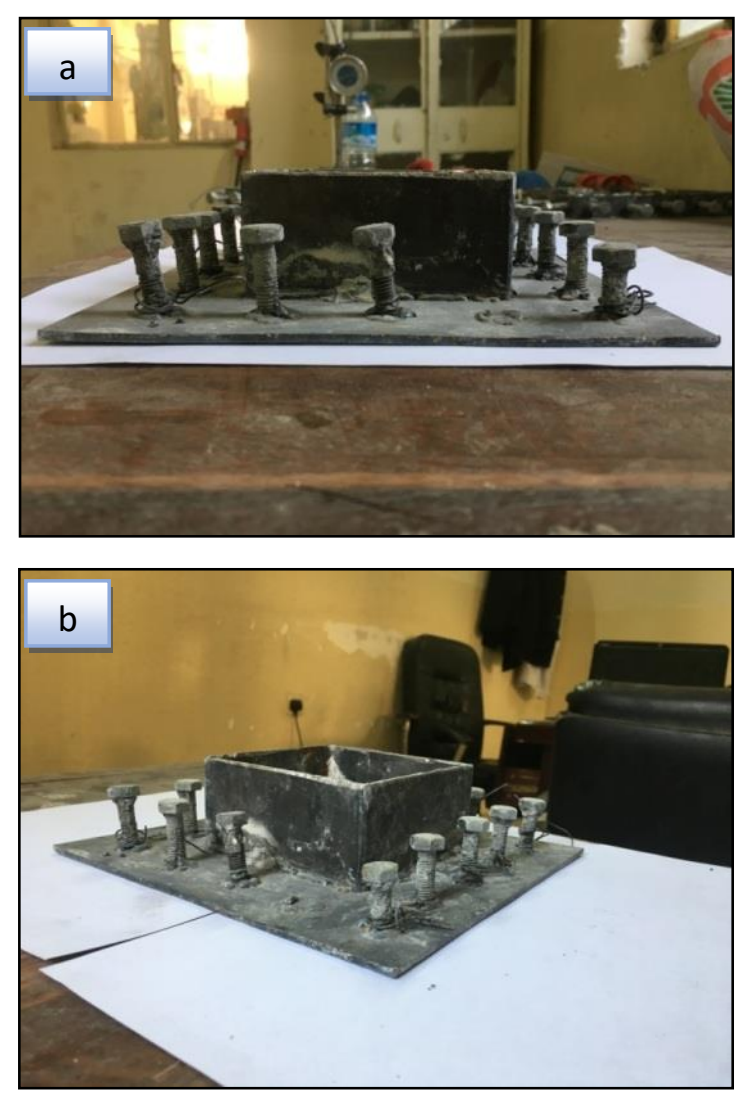

Figure 23. Localized Steel Plates after Testing

\section{Conclusions}

Based on the experimental results, generally, the torsional capacity has been deteriorated due to the existence of web opening, and it has been enhanced due to the contribution of the adopted technique, as follows:-

1- In this study, the findings lead to the conclusions, that the first cracking and ultimate torques for unstrengthened beam specimens that contain transverse openings at a distance (L/4) were decreased by about $(29.54 \%)$ and $(34.7 \%)$ respectively. While, when the openings move at a distance $(\mathrm{L} / 2)$ the first cracking and ultimate torques were decreased by about $(45.4 \%)$ and $(45.3 \%)$ respectively.

2-For the tested beam specimens which contain transverse opening at distance (L/4) and strengthened by localized steel plates, the first cracking, and ultimate torques were increased by $(9.68-32.25 \%)$ and $(34-55.5 \%)$ respectively; while, when the openings moves at distance $(\mathrm{L} / 2)$, the first cracking and ultimate torques were increased by (4.16-29.16\%) and (20-24\%) respectively. The localized steel plates work to curb the growth of the cracks near the corners of the transverse opening and transfer it towards outside the opening zone, so this leads to improved the torsional strength for the tested beams. Also, the strengthening by two-side localized steel plates is more efficient than the strengthening by one-side localized steel plates.

3-It may be concluded that the strain of the longitudinal bars and steel stirrups of the reference beam specimens (B-0-0.5L) in group two and (B-0$0.25 \mathrm{~L}$ ) in group three, represents the largest values; but not exceeds the yielding value, in compared to theoretically calculated yield strain value of $(\varepsilon y=2300 \times 10-6)$ and $(\varepsilon y=2481 \times 10-6)$ respectively for longitudinal bars and steel stirrups, this due to the presence of the web opening which represents a major source of weakness. And the smallest values of the strains for the strengthen beam specimens, due to the presence of the strengthening technique in these beams which represents as a source of enhancement.

\section{Acknowledgments}

The present work is an extension of the M. Sc. thesis of the first author. The authors wish to thanks with deep appreciation to the Department of Civil Engineering/College of Engineering/ALMustansiriyah University, for support in all stages of the study.

\section{Conflict of interest}

The authors undertake that the publication of this research will not cause any conflict of interest and that it meets all legislative requirements, and administrative mechanisms followed in this regard.

\section{References}

1. Hosseini, M., Ashrafi, H. R., Beiranvand, P., Ghanbari, B. (2016). Nonlinear analysis of torsion in reinforced concrete members after developing initial crack. Indian Journal of 
Science and Technology, Vol. 9, No.7, pp.117.

2. Soluit, A. K., Motawea M. A., Elsayed, K. M., Shalaby, S. H. (2007). Torsional behavior of $\mathrm{RC}$ beams strengthened with fiber reinforced polymer sheets, Mataria Engineering Research Journal, Vol.114, No.1, PP.102-119.

3. Ahmad, S., Azad, A. K., Hameed, M. A. (2008). A study of Self-Compacting Concrete Made with Marginal Aggregates. The Arabian Journal for Science and Engineering, Vol. 33, No.2, pp.437-442.

4. Al- Sa'idi, R. F. A. (2013). "Torsional Behavior Of Self Compacting Reinforced Concrete Beams", PhD Thesis, University of Al- Mustansiriya, Baghdad, Iraq.

5. Fawzy, K., Hashem, M. M., Elnady, A. M. (2014). Performance of RC beams with web opening subjected to pure torsion strengthened with CFRP. International Journal of Engineering and Innovative Technology. Vol.4, No.1, PP.197-204.

6. Waryosh, W. A., Al-Maliki, H. N., Munna, E. M. (2015). Torsional Behavior Of Reinforced Concrete Hollow Core Beams. Journal of Engineering and Development, Vol. 20, No.2, pp.72-88.

7. Mahdi, M. H. (2015). Behavior of High Strength Self Compacted Hollow Section Reinforced Concrete Beams under Pure Torsion. Tikrit Journal of Engineering Sciences, Vol.22, No.1, PP. 9-23.

8. Jabbar, S., Hejazi, F., Mahmod, H. M. (2016). Effect of an opening on reinforced concrete hollow beam web under torsional, flexural, and cyclic loadings. Latin American Journal of Solids and Structures, Vol.13, No.8, PP.1576-1595.

9. Kandekar, S. B., Talikoti, R. S. (2019) Torsional behaviour of reinforced concrete beam wrapped with aramid fiber. Journal of
King

Saud University-Engineering Sciences, Vol.31, No.4, PP.340-344.

10. Ali, H. A., Oday, H. H. (2018). Torsional Strength Evaluation of Reinforced SCC Box Beams Strengthened internally by Opened and Closed Transverse Concrete Diaphragms. MATEC Transverse of Conferences, Vol. 162, PP. 1-9.

11. Ali, H. A., Muhammad, H. A. (2018). Torsional Strength Enhancement of Reinforced SCC Box Beams using Internal Transverse Steel Bracing Technique. International Journal of Engineering and Technology, Vol.7, No.4.2,PP.299-306.

12. Hadhood, A., Gouda, M. G., Agamy, M. H., Mohamed, H. M., Sherif, A. (2020). Torsion in concrete beams reinforced with GFRP spirals. Engineering Structures, Vol.206, No.5, PP. 110-174.

13. EFNARC, 2002 Specification and Guidelines for Self-Compacting Concrete Association House, 99 West Street, Farnham, Surrey GU9 7EN, UK.

14. ACI Committee 318, Building Code Requirements for Structural Concrete (ACI $318 \mathrm{M}-14$ ) and commentary (ACI 318RM14) American Concrete Institute, Farmington Hills, MI, USA.

15. ASTM C39-01, (2001), "Test Method for Compressive Strength of Cylindrical Concrete Specimens", American Society for Testing and Materials, USA.

16. BS 1881-116, (1983), "Method for Determination of Compressive Strength of Concrete Cubes", British Standards Institute, London, UK.

17. ASTM C496-96, (1996), "Standard Test Method for Splitting Tensile Strength of Cylindrical Concrete Specimens", American Society for Testing and Material, USA.

18. ASTM C469-02, (2002), "Standard Test Method for Static Modulus of Elasticity and Poisson's Ratio of Concrete in Compression", 
American Society for Testing and Material, USA. 